\title{
The Coordination and Optimization of Closed-Loop Supply Chain with Lots of Factors
}

\author{
Chengdong SHI \\ School of Business, Shandong University of Technology, Zibo 255000, China \\ E-mail: scd0211@163.com \\ Guanglu ZHOU \\ Department of Maths and Statistics, Curtin University, Perth, Australia \\ Dunxin BIAN \\ School of Electrical and Electronic Engineering, Shandong University of Technology, Zibo 255000, \\ China \\ Meixiang WU \\ School of Business, Shandong University of Technology, Zibo 255000, China
}

\begin{abstract}
Consider a closed-loop supply chain including a manufacturer, a retailer and two third party recyclers as the background. A coordination and optimization model is built by using the downside-risk function, Cournot model and government subsidy excitation function. The effect of risk characteristics, government subsidy and Cournot competition on supply chain is analyzed, and the impact of revenueand-expense sharing contract is studied in the channel, which shows that the contract cannot coordinate and optimize the closed-loop supply chain. Also, risk sharing contract and expense sharing contract are designed, which can offer the desired downside protection to the retailer, provide more profits to the agents, and accomplish channel coordination and optimization. Moreover, an application example is given for testing the effectiveness and feasibility of the contract, and the bound and rule of the contract parameters are given. Finally, by the analysis of numerical simulation and sensitivity of the model based on the contract, the validity and practicability of the model are verified, and the relationship between government subsidy, risk characteristics, competitive characteristics with the supply chain is obtained. This study provides decision support and decision-making reference for the development of remanufacturing industry.
\end{abstract}

Keywords downside-risk; government subsidy; Cournot competition; coordination and optimization

\section{Introduction}

The closed-loop supply chain management has been a major issue because of the resources, environmental challenges, extended producer responsibility and the profits from remanufactur-

Received September 5, 2015, accepted October 30, 2015

Supported by the National Natural Science Foundation Program of Shandong Province (ZR2013GM001), Humanities and Social Sciences Project of Chinese Ministry of Education (16YJAZH053, 13YJAZH12), the Social Science Research Project of Shandong Province (11CGLZ07, 12CGLZ10), the Humanities and Social Sciences Development Foundation of Shandong University of Technology (2010ZDXM07), the Doctoral Scientific Research Program of Shandong University of Technology (2011KQ08) 
ing. Thus, research on closed-loop supply chain has been becoming a hot issue in recent years. References [1-5] are representative literatures in the certain market demand. While in the uncertain market demand, references [6, 7] have studied risk-neutral supply chain (manufacturer and retailer are both risk-neutral), research literatures [8-11] have studied retailer risk averse situation in the open-loop supply chain, Shi, et al. ${ }^{[12]}$ have studied a single third-party recycler remanufacturing closed-loop supply chain by using downside-risk function.

The operation of the supply chain under retailer competition was analyzed in [4], but this paper did not consider the retailer risk averse. The economic policy was treated as an exogenous variable for the analysis of its impact on the supply chain in [5]. The risk averse characteristic was analyzed in [12], but the competition characteristic and the government subsidy effect have not been studied.

In this paper, we will do some new work on the basis of the above documents by combining the government subsidy, competition and risk aversion characteristic with the decision function of the supply chain. Also we will analyze the integrated effects of every possible factors on the supply chain comprehensively and then design the supply chain coordination and optimization mechanisms.

\section{Problem Description and Notation}

The model considered in this paper is composed of a manufacturer, a retailer and two thirdparty recyclers. The following five questions are addressed by the model: 1) What is the game law among the agents based on the comprehensive analysis of the risk aversion and the competitive nature in closed-loop supply chain? 2) What is the impact of risk aversion characteristic on the closed-loop supply chain? 3) What is the variation law between decision variables like transfer price, recycling price etc. with competition characteristic? 4) What is the effect of government subsidy on the closed-loop supply chain? 5) How can we design coordination and optimization mechanisms in the circumstance of considering a variety of factors?

In the following, we give a list of notation used in this paper.

$p$-product selling price;

$w$-product wholesale price;

$w^{s}$-product wholesale price in the supply chain coordination state;

$c_{m}$-product cost price with fresh raw materials;

$c_{r}$-product cost price with recycled waste materials;

$c_{s}$-government subsidy;

$b_{3 p}$-waste product recycling price;

$b_{3 p}^{s}$-waste product recycling price in the supply chain coordination state;

$b_{m}$-waste material transfer price of the third-party paid by the manufacturer;

$b_{m}^{s}$-waste material transfer price of the third-party paid by the manufacturer in the supply chain coordination state;

$G\left(b_{3 p}\right)$-waste material recycling quantity;

$G\left(b_{3 p}^{s}\right)$-waste material recycling quantity in the supply chain coordination state;

$q$-order quantity;

$X$-product market demand; 
$E\left(\pi_{r}\right)$-retailer expected profit;

$E\left(\pi_{r}^{s}\right)$-retailer's expected profit in the supply chain coordination state;

$E\left(\pi_{m}\right)$-manufacturer's expected profit;

$E\left(\pi_{m}^{s}\right)$-manufacturer's expected profit in the supply chain coordination state;

$E\left(\pi_{3 p}\right)$-expect profit of third-party recycling company;

$E\left(\pi_{3 p}^{s}\right)$-expect profit of third-party recycling company in the supply chain coordination state;

$E(\pi)$-expected profit of the closed-loop supply chain;

$E\left(\pi^{s}\right)$-expected profit of the closed-loop supply chain in the coordination state.

\section{Decentralized Decision-Making Model}

On the basis of references $[4,13]$, the recycling quantity function is

$$
G\left(b_{3 p i}\right)=k+h b_{3 p i}-\gamma b_{3 p j},
$$

where $i=1,2, j=3-i$, and $\gamma$ is an alternative coefficient between the two third-party recyclers. Decentralized decision-making model is

$$
\left\{\begin{array}{l}
\max E\left(\pi_{m}\right) \\
\max E\left(\pi_{3 p 1}\right) \\
\max E\left(\pi_{3 p 2}\right) \\
\max E\left(\pi_{r}\right)
\end{array}\right.
$$

The constraint condition is

$$
P\left\{\pi_{r} \leq \alpha\right\} \leq \beta .
$$

In (1), the retailer's expected profit function is

$$
E\left(\pi_{r}\right)=p\left(q-\int_{0}^{q} F(x) \mathrm{d} x\right)-w q,
$$

$\beta$ is the confidence level ${ }^{[14]}$. The expected profit functions of third-party recyclers are

$$
\begin{aligned}
& \max E\left(\pi_{3 p 1}\right)=\left(b_{m}-b_{3 p 1}\right)\left(k+h b_{3 p 1}-\gamma b_{3 p 2}\right), \\
& \max E\left(\pi_{3 p 2}\right)=\left(b_{m}-b_{3 p 2}\right)\left(k+h b_{3 p 2}-\gamma b_{3 p 1}\right) .
\end{aligned}
$$

The expected profit function of manufacturer is

$$
\max E\left(\pi_{m}\right)=\left(w-c_{m}\right) q+\sum_{i=1}^{2}\left(\Delta+c_{s}-b_{m}\right) G\left(b_{3 p i}\right) .
$$

According to (3) and (4),

$$
b_{3 p 1}=b_{3 p 2}=\frac{h b_{m}-k}{2 h-\gamma}
$$

From (5) and (6), we have

$$
\left\{\begin{array}{l}
b_{m}^{d}=\frac{(h-\gamma)\left(\Delta-c_{s}\right)-k}{2(h-\gamma)} \\
b_{3 p i}^{d}=\frac{2 k \gamma-3 h k+\left(h^{2}-h \gamma\right)\left(\Delta+c_{s}\right)}{2(h-\gamma)(2 h-\gamma)}
\end{array}\right.
$$


To ensure that $b_{m}^{d}>0$ and $b_{3 p i}^{d}>0$, the following conditions must be satisfied:

$$
\left\{\begin{array}{l}
k<\frac{h\left(\Delta+c_{s}\right)}{3}, \\
\gamma<\frac{h^{2}\left(\Delta+c_{s}\right)-3 h k}{h\left(\Delta+c_{s}\right)-2 k}<h .
\end{array}\right.
$$

Therefore, the optimal expected profits of manufacturer, retailer and third-party are as follows:

$$
\left\{\begin{array}{l}
E\left(\pi_{r}^{d}\right)=p\left(q^{d}-\int_{0}^{q^{d}} F(x) \mathrm{d} x\right)-w^{d} q^{d}, \\
E\left(\pi_{3 p i}^{d}\right)=\frac{h\left(k+(h-\gamma)\left(\Delta+c_{s}\right)\right)^{2}}{4(2 h-\gamma)^{2}} \\
E\left(\pi_{m}^{d}\right)=\left(w^{d}-c_{m}\right) q^{d}+\frac{h\left(k+(h-\gamma)\left(\Delta+c_{s}\right)\right)^{2}}{2(h-\gamma)(2 h-\gamma)} .
\end{array}\right.
$$

\subsection{The Effects of Government Subsidy and Cournot Competition}

Theorem 1 The manufacture's optimal expected profit, the third-party's optimal expected profit, the recycling price of waste product, the manufacturer's transfer price are positive related with government subsidy. The retailer's optimal expected profit, product selling price and the wholesale price are unrelated with the government subsidy.

Proof By simple computation, we have

$$
\begin{aligned}
& \frac{\partial E\left(\pi_{m}^{d}\right)}{\partial c_{s}}=\frac{h\left(k+(h-\gamma)\left(\Delta+c_{s}\right)\right)}{2 h-\gamma}, \\
& \frac{\partial E\left(\pi_{3 p i}^{d}\right)}{\partial c_{s}}=\frac{h(h-\gamma)\left(k+(h-\gamma)\left(\Delta+c_{s}\right)\right)}{2(2 h-\gamma)^{2}}, \\
& \frac{\partial b_{3 p i}^{d}}{\partial c_{s}}=\frac{h}{2(2 h-\gamma)} .
\end{aligned}
$$

According to (7) and (9), $\frac{\partial E\left(\pi_{m}^{d}\right)}{\partial c_{s}}>0, \frac{\partial E\left(\pi_{3 p i}^{d}\right)}{\partial c_{s}}>0, \frac{\partial E\left(\pi_{r}^{d}\right)}{\partial c_{s}}=0, \frac{\partial b_{3 p i}^{d}}{\partial c_{s}}>0, \frac{\partial b_{m}^{d}}{\partial c_{s}}>0, \frac{\partial p^{d}}{\partial c_{s}}>0$, and $\frac{\partial w^{d}}{\partial c_{s}}>0$. So, Theorem 1 holds.

Theorem 2 The manufacturer's and the third-party's optimal expected profit, the recycling price of waste product and the manufacturer's transfer price are negative related with competition coefficient. The retailer's optimal expected profit, product selling price and wholesale price have nothing to do with competition coefficient.

Proof

$$
\begin{aligned}
& \frac{\partial E\left(\pi_{m}^{d}\right)}{\partial \gamma}=\left(-2 k+h\left(\Delta+c_{s}\right)\right) \gamma+3 h k-h^{2}\left(\Delta+c_{s}\right) \\
& \frac{\partial E\left(\pi_{3 p i}^{d}\right)}{\partial \gamma}=\frac{2 h\left(k+(h-\gamma)\left(\Delta+c_{s}\right)\right)\left(k-h\left(\Delta+c_{s}\right)\right)}{4(2 h-\gamma)^{3}} \\
& \frac{\partial b_{m}^{d}}{\partial \gamma}=\frac{-k}{2(h-\gamma)^{2}}, \\
& \frac{\partial b_{3 p i}^{d}}{\partial \gamma}=\frac{\left(-2 k+h\left(\Delta+c_{s}\right)\right) \gamma^{2}+\left(6 h k-2 h^{2}\left(\Delta+c_{s}\right)\right) \gamma-5 h^{2} k+h^{3}\left(\Delta+c_{s}\right)}{2(h-\gamma)^{2}(2 h-\gamma)^{2}} .
\end{aligned}
$$


According to (7), (8) and (9), $\frac{\partial E\left(\pi_{m}^{d}\right)}{\partial \gamma}<0, \frac{\partial E\left(\pi_{3 p i}^{d}\right)}{\partial \gamma}<0, \frac{\partial E\left(\pi_{r}^{d}\right)}{\partial \gamma}=0, \frac{\partial b_{m}^{d}}{\partial \gamma}<0$, and $\frac{\partial p^{d}}{\partial \gamma}=0$. Theorem 2 is proved.

$\frac{\partial b_{3 p i}^{d}}{\partial \gamma}$ is much complicated, so we will do some simulation with Matlab 8.0 later.

\subsection{The Effect of Retailer's Risk Characteristic}

Proposition 1 For any target profit level q, there is a critical order quantity:

$$
q^{0}=\frac{\alpha}{p-w} .
$$

When the order quantity satisfies $q<q^{0}$, the downside-risk is 1 . When $q \geq q^{0}$, the downside-risk is $F\left(\frac{\alpha+w q}{p}\right)$, which is an increasing function of $q$.

Proof When the order quantity is $q<q^{0}$, because of $\min (q, X)=q$, the retailer's profit is $\prod(q, X)=(p-w) q<(p-w) q^{0}=\alpha$. Therefore, the probability of being unable to finish the target profit level is $100 \%$. When $q \geq q^{0}$ and $X>q$, the retailer's profit increases with order quantity monotonically. The actual profit must be greater than the target profit. That is, the probability of being unable to finish the target profit level is 0 . Therefore,

$$
P\left(\prod(q, X) \leq \alpha\right)=P(p X-w q \leq \alpha)=F\left(\frac{\alpha+w q}{p}\right),
$$

obviously, the downside-risk increases with variable $q$.

Proposition 2 For the risk-averse pair $(\alpha, \beta)$, the optimal order quantity is

$$
q^{*}= \begin{cases}q^{d}, & \beta \geq F\left(\frac{\alpha+w q^{d}}{p}\right), \\ \frac{p F^{-1}(\beta)-\alpha}{w}, & F\left(q^{0}\right)<\beta<F\left(\frac{\alpha+w q^{d}}{p}\right) .\end{cases}
$$

where $q^{d}$ satisfies $q^{d}=F^{-1}\left(\frac{\alpha+w q^{d}}{p}\right)$.

Proof When $\beta \geq F\left(\frac{\alpha+w q^{d}}{p}\right), P\left(\prod\left(q^{d}, X\right) \leq \alpha\right)=F\left(\frac{\alpha+w q^{d}}{p}\right) \leq \beta$. Here, the optimal order quantity $q^{d}$ satisfies (1), which is the optimal solution. When $F\left(q^{0}\right)<\beta<F\left(\frac{\alpha+w q^{d}}{p}\right)$, $P\left(\prod(q, X) \leq \alpha\right)=F\left(\frac{\alpha+w q}{p}\right) \leq \beta, q \leq \frac{p F^{-1}(\beta)-\alpha}{w}=q^{*}$.

In order to maximize the retailer's expect profit, we take $q=q^{*}$. Then, the probability of retailer's profit which is less than target profit level $\alpha$ is

$$
P\left(\prod\left(q^{*}, X\right) \leq \alpha\right)=F\left(\frac{\alpha+w q^{*}}{p}\right)=\beta .
$$

Here, $q^{*}$ is less than $q^{d}$, which is a feasible solution. When $F\left(q^{0}\right)>\beta$, the downside risk is 1 , which means the retailer does not order certainly, and the problem does not have a feasible solution.

\section{Centralized Decision-Making Model}

In this case, the optimal objective function is

$$
\max E(\pi)=p\left(q-\int_{0}^{q} F(x) \mathrm{d} x\right)-c_{m} q+\sum_{i=1}^{2}\left(\Delta+c_{s}-b_{3 p i}\right) G\left(b_{3 p i}\right) .
$$


The optimal order quantity and optimal recycling price are

$$
\begin{aligned}
& q^{c}=F^{-1}\left(\frac{p-c_{m}}{p}\right), \\
& b_{3 p i}^{c}=\frac{(h-\gamma)\left(\Delta+c_{s}\right)-k}{2(h-\gamma)} .
\end{aligned}
$$

Therefore, the optimal expected profit is

$$
E\left(\pi^{c}\right)=p\left(q-\int_{0}^{q} F(x) \mathrm{d} x\right)-c_{m} q^{c}+\frac{\left(k+(h-\gamma)\left(\Delta+c_{s}\right)\right)^{2}}{2(h-\gamma)} .
$$

Theorem $3 b_{3 p i}^{d}<b_{3 p i}^{c}, w^{d}<p^{d}, b_{3 p i}^{d}<b_{m}^{d}, q^{d}<q^{c}$.

Proof By (7) and (14), $b_{m}^{d}-b_{3 p i}^{d}>0, b_{m}^{d}=b_{3 p i}^{c}$. In decentralized decision-making model, $c_{m}<w^{d}<p^{d}$. Therefore, from (14), $q^{c}>q^{d}$. Theorem 3 is proved.

Theorem 4 The optimal expected profit of the closed-loop supply chain, the recycling price of waste product are negative related with the third party's competition coefficient.

Proof

$$
\begin{aligned}
& \frac{\partial b_{3 p i}^{c}}{\partial \gamma}=\frac{-k}{2(h-\gamma)^{2}}, \\
& \frac{\partial E\left(\pi^{c}\right)}{\partial \gamma}=\frac{\left(k+(h-\gamma)\left(\Delta+c_{s}\right)\right)\left(k-(h-\gamma)\left(\Delta+c_{s}\right)\right)}{2(h-\gamma)^{2}} .
\end{aligned}
$$

According to (14), $\frac{\partial E\left(\pi^{c}\right)}{\partial \gamma}<0, \frac{\partial b_{3 p i}^{c}}{\partial \gamma}<0$. Theorem 4 is proved.

\section{Effect of Retailer's Risk Aversion Under Revenue and Expense Sharing Contract}

The form of revenue and expense sharing contract is $\left(w^{s}, \phi_{1}, \phi_{2}, b_{m}^{s}\right)$. Here, $w^{s}$ is the manufacturer's wholesale price. $\phi_{1}$ is the revenue sharing proportion between retailer and manufacturer. $\phi_{2}$ is the expense sharing proportion between the third-party and the manufacturer, $b_{m}^{s}$ is the transfer price, $\phi_{1}, \phi_{2} \in(0,1)$. Based on the idea and method of reference [15], when $w^{s}=\phi_{1} c_{m}, b_{m}^{s}=\phi_{2}\left(\Delta+c_{s}\right)$, revenue and expense sharing contract can make the risk-neutral closed-loop supply chain considering government subsidy and Cournot competition achieve perfect coordination. The optimal expected profit of third-party and the manufacturer is

$$
\left\{\begin{aligned}
E\left(\pi_{3 p i}^{s}\right)= & \phi_{2} \frac{(h-\gamma)\left(\Delta+c_{s}\right)\left(k+(h-\gamma)\left(\Delta+c_{s}\right)\right)}{E\left(\pi_{m}^{s}\right)=}\left(1-\phi_{1}\right) p\left(q^{c}-\int_{0}^{q^{c}} F(x) \mathrm{d} x\right) \\
& +\left(w^{s}-c_{m}\right) q^{c}+\frac{\left(k+(h-\gamma)\left(\Delta+c_{s}\right)\right)^{2}}{2(h-\gamma)} \\
& -\phi_{2} \frac{(h-\gamma)\left(\Delta+c_{s}\right)\left(k+(h-\gamma)\left(\Delta+c_{s}\right)\right)}{2 h} .
\end{aligned}\right.
$$

Now then, when considered retailer's risk aversion characteristic, can the closed-loop supply chain still achieve the perfect coordination under the revenue and expense sharing contract? 
Proposition 3 Under the revenue and expense sharing contract, the optimal order quantity with the downside risk constraints is

$$
q^{d}= \begin{cases}q^{c}, & \beta \geq F\left(\frac{\alpha+w^{s} q^{c}}{\phi_{1} p}\right), \\ \frac{\phi_{1} p F^{-1}(\beta)-\alpha}{w^{s}}, & F\left(q^{0}\right)<\beta<F\left(\frac{\alpha+w^{s} q^{c}}{\phi_{1} p}\right) .\end{cases}
$$

$q_{r}^{d}$ is the retailer's optimal order quantity under the revenue and expense sharing contract. $q^{c}$ is the optimal order quantity under centralized decision-making model. The detailed analysis process of (17) refers to Proposition 2. According to the analysis, when using Downside-risk method to measure the retailer's risk aversion characteristic, the revenue and expense sharing contract cannot make the supply chain coordinated perfectly.

\section{Coordination and Optimization of the Closed-Loop Supply Chain}

\subsection{Risk Sharing Contract}

The expense sharing contract is still implemented between the manufacturer and the thirdparty. Risk sharing contract is implemented between the manufacturer and retailer. Risk sharing contract consists of two parts: revenue-sharing contract and additional terms (compensation strategies). $q_{r}^{d}$ is the optimal order quantity under the risk-averse characteristic $(\alpha, \beta)$. As in (17), the optimal order quantity decreases continuously continues with the increases of risk aversion degree. If $q_{r}^{d}=q^{c}$ the closed-loop supply chain has been coordinated. For generality, we assume $q_{r}^{d}<q^{c}$, according to $(17), P\left(\pi_{r}^{s}\left(q_{r}^{d}, X\right) \leq \alpha=\beta\right)$, the additional terms are as follows:

(i) If $q^{0}<q \leq q_{r}^{d}$, the revenue sharing contract is still executed.

(ii) If $q_{r}^{d}<q \leq q^{c}$, in addition to the revenue sharing contract with an $q_{r}^{d}$, the retailer pays the wholesale price $w^{*}$ for each unit in excess of $q_{r}^{d}$, and it also gains compensation of $w^{*}$ for each unsold unit.

(iii) If $q>q^{c}$, the terms of the contract are the same as that in (ii), except that the refundable number cannot exceed.

Now then, the retailer's profit function is constructed as follows:

(i) If $q^{0}<q \leq q_{r}^{d}$, the retailer's profit function is $\pi_{r}^{s}(q, X)$. The order quantity has not reach the optimal order quantity, so the closed-loop supply chain could not be coordinated.

(ii) If $q_{r}^{d}<q \leq q^{c}$, the profit function is

$$
\begin{cases}\pi_{r}^{s}\left(q_{r}^{d}, X\right), & X \leq q_{r}^{d} \\ \pi_{r}^{s}\left(q_{r}^{d}, X\right)+\left(p-w^{*}\right)\left(X-q_{r}^{d}\right), & q_{r}^{d}<X \leq q \\ \pi_{r}^{s}\left(q_{r}^{d}, X\right)+\left(p-w^{*}\right)\left(q-q_{r}^{d}\right), & X>q\end{cases}
$$

The expected profit is

$$
E\left(\pi_{r}^{s}\left(q_{r}^{d}, X\right)\right)+\left(p-w^{*}\right)\left(\int_{q_{r}^{d}}^{q^{c}}\left(x-q_{r}^{d}\right) F(x) \mathrm{d} x+(1-F(q))\left(q-q_{r}^{d}\right)\right) .
$$


(iii) If $q>q^{c}$, the profit function is

$$
\begin{cases}\pi_{r}^{s}\left(q_{r}^{d}, X\right)-w^{*}\left(q-q^{c}\right), & X \leq q_{r}^{d}, \\ \pi_{r}^{s}\left(q_{r}^{d}, X\right)+\left(p-w^{*}\right)\left(X-q_{r}^{d}\right)-w^{*}\left[(q-X)-\left(q^{c}-q_{r}^{d}\right)\right]^{+}, & q_{r}^{d}<X \leq q, \\ \pi_{r}^{s}\left(q_{r}^{d}, X\right)+\left(p-w^{*}\right)\left(q-q_{r}^{d}\right), & X>q .\end{cases}
$$

In this case, since

$$
\begin{aligned}
& P\left(\pi_{r}^{s}(q, X) \leq \alpha\right) \geq P\left(\pi_{r}^{s}(q, X) \leq \alpha\right) \cap\left(X \leq q_{r}^{d}\right) \\
= & P\left(\pi_{r}^{s}\left(q_{r}^{d}, X\right)-w^{*}\left(q-q^{c}\right) \leq \alpha\right)>P\left(\pi_{r}^{s}\left(q_{r}^{d}, X\right) \leq \alpha\right) \\
= & \beta
\end{aligned}
$$

the retailer's downside-risk constraint is not satisfied. Therefore, the retailer would not order a quantity $q$ such that $q>q^{c}$.

Proposition 4 To ensure that the retailer and the manufacture have incentives to enter into a risk-sharing contract, the lower bound and the upper bound of $w^{*}$ are

$$
\frac{c_{m}\left(q-q_{r}^{d}\right)}{\left(q-q_{r}^{d}\right)-\int_{q_{r}^{d}}^{q} F(x) \mathrm{d} x} \leq w^{*} \leq p
$$

Proof The results can be directly obtained from

$$
\Delta_{r}\left(w^{*}, q\right)=\left(p-w^{*}\right)\left(\int_{q_{r}^{d}}^{q}\left(x-q_{r}^{d}\right) F(x) \mathrm{d} x+(1-F(q))\left(q-q_{r}^{d}\right)\right) \geq 0
$$

and

$$
\Delta_{m-r}\left(w^{*}, q\right)=w^{*}\left(\int_{q_{r}^{d}}^{q}\left(x-q_{r}^{d}\right) F(x) \mathrm{d} x+(1-F(q))\left(q-q_{r}^{d}\right)\right)-c_{m}\left(q-q_{r}^{d}\right) \geq 0 .
$$

Now, we continue to prove that risk-sharing and expense sharing contract can coordinate the closed-loop supply chain.

\subsection{Risk Sharing Contract and Expense Sharing Contract}

Theorem 5 For any risk aversion pair $(\alpha, \beta)$, if $w^{*}$ is within the scope of $(22)$, then the combination of risk-sharing contract and expense-sharing contract can make the supply chain coordinated perfectly.

Proof (i) According to (9), (16), (23) and (24), the expected profits of retailer, manufacturer and third-party are more than their reservation payoffs.

(ii) If a retailer orders $q_{r}^{d}$ quantity, then according to Proposition 3, the downside-risk is

$$
P\left(\pi_{r}^{s}\left(q_{r}^{d}, X\right) \leq \alpha\right)=\beta
$$

For any order quantity $q, q_{r}^{d}<q \leq q^{c}$, the retailers downside-risk is

$$
P\left(\pi_{r}^{s}(q, X) \leq \alpha\right)=P\left(\pi_{r}^{s}\left(q_{r}^{d}, X\right) \leq \alpha\right)=\beta .
$$


Therefore, the retailer's downside-risk constraint is satisfied under the risk-sharing contract and expense-sharing contract.

For any order quantity $q, q^{0}<q \leq q_{r}^{d}$ or $q>q^{c}$, the closed-loop supply chain is not coordinated based on above analysis.

(iii) From (19), the expected profit of the retailer is increasing for $q_{r}^{d}<q \leq q^{c}$. In addition, ordering quantity exceeding $q^{c}$ violates it's downside-risk constraint, since the regulation of the contract is that the maximum return quantity is less than $q^{c}-q_{r}^{d}$. Therefore, the retailer would order $q^{c}$, which maximizes its expected profit subject to its downside-risk constraint. When the retailer orders $q^{c}$, the closed-loop supply chain's profit is also maximized. The closed-loop supply chain is coordinated.

\subsection{Incentive and Risk Analysis}

With the risk-sharing contract and expense-sharing contract, the retailer's order quantity could increase to the optimal order quantity $q^{c}$, and the recycling price of the waste product could reach the optimal recycling price $b_{3 p i}^{c}$, so the closed-loop supply chain could achieve coordination and optimization. The retailer's expected profit increases by the amount $\Delta_{r}\left(w^{*}, q^{c}\right)$, but its downside risk does not increase because it gets a full refund for all unsold products above the quantity $q_{r}^{d}$. The manufacturer undertakes more risk due to taking compensation strategy, but it also gets the additional expected profit of $\Delta_{m-r}\left(w^{*}, q^{c}\right)$ for bearing that risk. The third-party's expected profit is increased by

$$
\phi_{2} \frac{(h-\gamma)\left(\Delta+c_{s}\right)\left(k+(h-\gamma)\left(\Delta+c_{s}\right)\right)}{4 h}-h \frac{\left(k+(h-\gamma)\left(\Delta+c_{s}\right)\right)^{2}}{4(2 h-\gamma)^{2}} .
$$

\section{Numerical Simulations and Sensitivity Analysis}

Assume that parameters of an electronic product closed-loop supply chain are as follows: $c_{m}=5, c_{r}=2, c_{s}=1, p=12, h=100, k=50$. The market demand $X$ is uniform distribution, $X \sim U(A, B), A=200, B=1000$. Take the competition factor $\gamma=30$.

\subsection{Numerical Simulations}

Assume that $\alpha$ is the retailer's expected profit of the risk-neutral closed loop supply chain under revenue and expense sharing contract, and the downside risk measure coefficient $\beta$ is 0.33 , then we get the results in Table 1 .

Table 1 Results of closed-loop supply chain with different contracts

\begin{tabular}{ccccccc}
\hline \multicolumn{2}{l}{ revenue-expense sharing contract } & \multicolumn{4}{l}{ risk-sharing and expense-sharing contract } \\
\hline$w_{s}$ & $q_{r}^{d}$ & $\beta$ & $\Delta_{m-r}\left(w^{*}, q^{c}\right)$ & $\Delta_{r}\left(w^{*}, q^{c}\right)$ & $w^{*}$ & $q^{c}$ \\
$5 \phi_{1}$ & 507 & 0.33 & 332.7 & 263.4 & 10 & 667 \\
\hline
\end{tabular}

From Table 1, the retailer's order did not reach the optimal order quantity under revenue and expense sharing contract. This indicates that the revenue and expense sharing contract does completely inhibit retailer's risk aversion. Therefore, the closed-loop supply chain did not achieve coordination. It verifies the conclusions of Section 5. But under the risk-sharing and expense sharing contract, the retailer's order quantity reaches the optimal value, also both 
retailer's profit and manufacturer's profit increase. Therefore, the supply chain achieves perfect coordination. This analysis is consistent with the result in Section 6 .

\subsection{Matlab Simulations}

In this section, we use Matlab 8.0 to simulate the effects of competition coefficient and government subsidy on the closed-loop supply chain, which could provide the visual image analysis. The simulation results are shown in Figures 1-6.

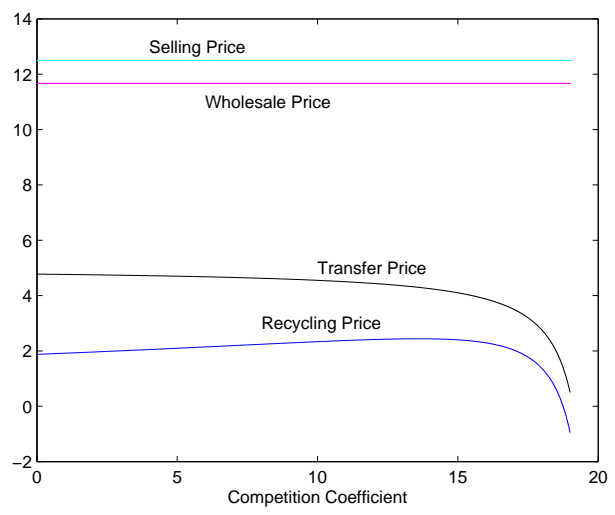

Figure 1 Relationship between variables with competition coefficient in decentralized decision-making model

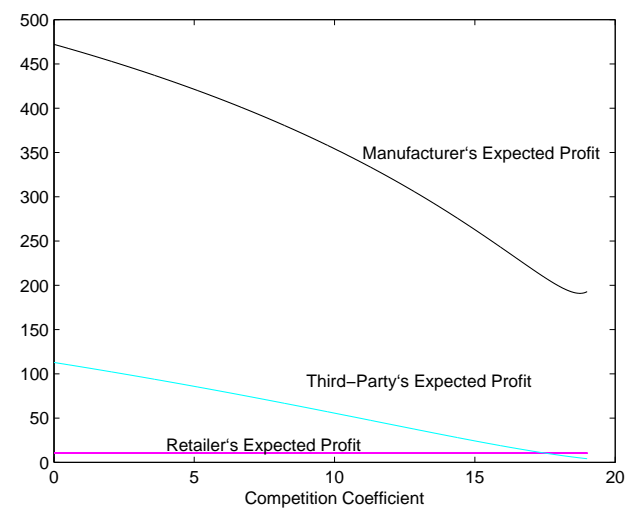

Figure 2 Relationship between expected-profits of manufacturer, third-party and retailer with competition coefficient in decentralized decision-making model 


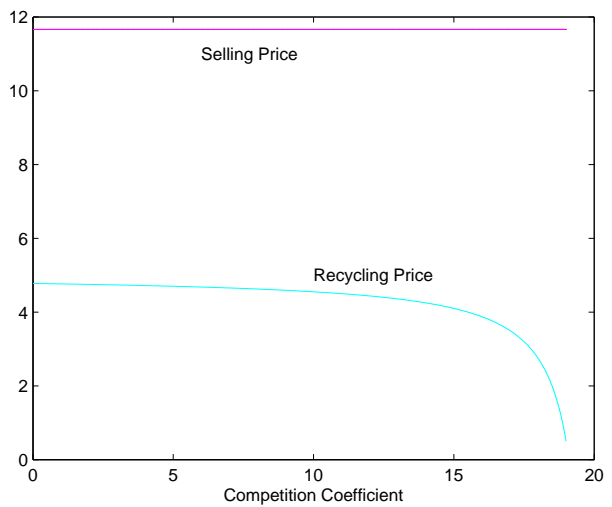

Figure 3 Relationship between selling price and recycling price with competition coefficient in centralized decision-making model

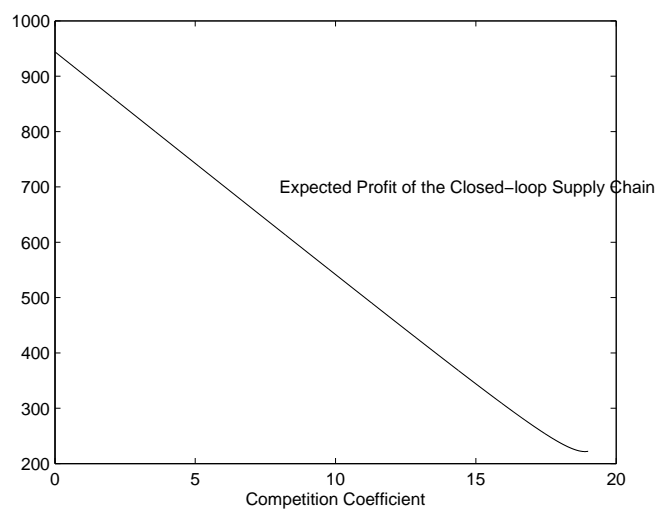

Figure 4 Relationship between expected profit of the closed-loop supply chain with competition coefficient in centralized decision-making model

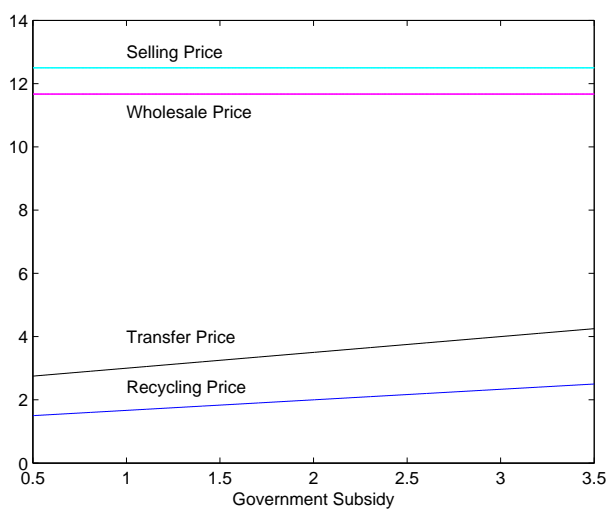

Figure 5 Relationship between variables with government subsidy in decentralized decision-making model 


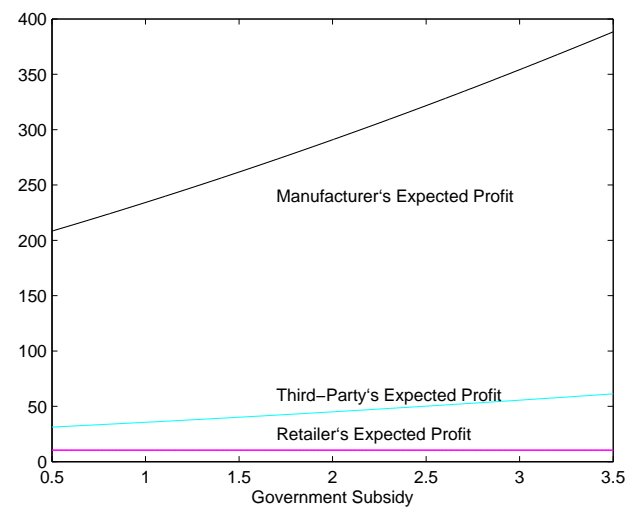

Figure 6 Relationship between expected-profits of manufacturer, third-party and retailer with government subsidy in decentralized decision-making model

From Figures 1 and 2, we can see that recycling price is positive correlation with competition coefficient, but the transfer price, the third-party's expected profit, manufacturer's expected profit are negatively correlated with competition coefficient. This indicates that competition reduces the transfer price and the profits of third party and manufacturer, but improves the consumer's utilities and raised the recycling amount of waste products. Figures 3 and 4 show that the optimal recycling price and the expected profit of the closed-loop supply chain are negatively correlated with competition coefficient, which indicates that competition reduces the recycling price and the expected profit of the closed-loop supply chain. The result coincides with the analysis of Theorem 2. From Figure 5, we can see that the recycling price and transfer price are all positively correlated with government subsidy. The selling price is not associated with the government subsidy, which means that the government subsidy is incentive for recycling waste product, but is not incentive for product sales. Figure 6 shows that retailer's expected profit is unrelated with government subsidy. The third-party's expected profit, manufacturer's expected profit are all positively associated with government subsidy. So, government subsidy is incentive not only to manufacturer, but also to the third party.
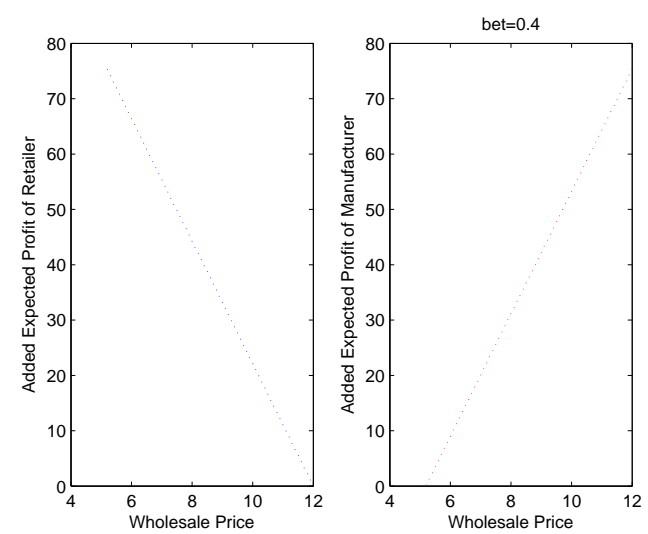

Figure 7 Relationship between added expected-profits of retailer and manufacturer with wholesale price 


\subsection{Sensitivity Analysis}

The sensitivity analysis results of parameter $w^{*}$ and $\beta$ are shown in Tables 2 and 3 . The simulation results are demonstrated in Figures 7 and 8.
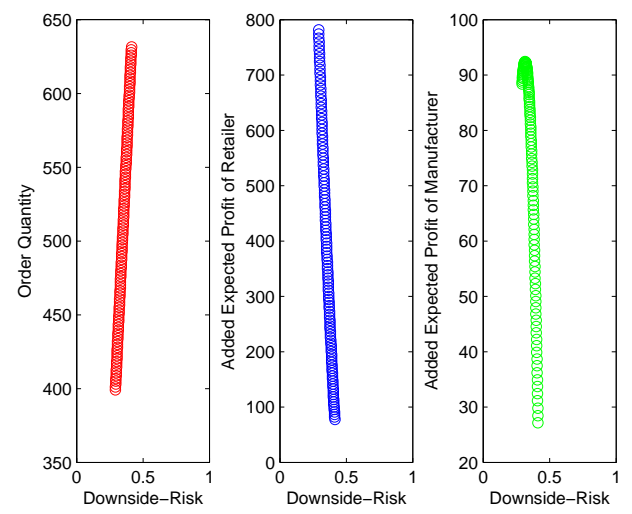

Figure 8 Relationship between order quantity, added expectedprofits of manufacturer and retailer with downside-risk

From Table 2, we can see that added expected profit of manufacturer increases with $w^{*}$, but added expected profit of retailer declines with $w^{*}$. Table 3 shows that $q_{r}^{d}$ declines with $\beta$, but added expected profits of manufacturer and retailer increase with $\beta$. From Figure 7 , we can see that the added profit of retailer is negatively correlated with wholesale price $w^{*}$, but the added profit of manufacturer is positively correlated with the wholesale price $w^{*}$, which verifies the results of sensitivity analysis in Table 2. Figure 8 shows that the order quantity is negatively correlated with the downside risk $\beta$, the added profits of retailer and manufacturer added profit are both positively correlated with downside risk $\beta$. This verifies the results of sensitivity analysis in Table 3 .

Table 2 The effect of parameter $w^{*}$

\begin{tabular}{cccccc}
\hline$w^{*}$ & $\Delta_{m-r}\left(w^{*}, q^{c}\right)$ & $\Delta_{r}\left(w^{*}, q^{c}\right)$ & $\beta$ & $q_{r}^{d}$ & $q^{c}$ \\
\hline 7 & 73.64 & 298.6 & 0.35 & 545 & 667 \\
9 & 193.1 & 179.2 & 0.35 & 545 & 667 \\
11 & 321.5 & 59.7 & 0.35 & 545 & 667 \\
\hline
\end{tabular}

Table 3 The effect of parameter $\beta$

\begin{tabular}{cccccc}
\hline$w^{*}$ & $\Delta_{m-r}\left(w^{*}, q^{c}\right)$ & $\Delta_{r}\left(w^{*}, q^{c}\right)$ & $\beta$ & $q_{r}^{d}$ & $q^{c}$ \\
\hline 8 & 30.76 & 43.68 & 0.4 & 641 & 667 \\
8 & 133.4 & 238.9 & 0.35 & 641 & 667 \\
8 & 212.8 & 480.1 & 0.3 & 641 & 667 \\
\hline
\end{tabular}




\section{Conclusions}

This paper established a closed-loop supply chain coordination and optimization model by using the downside-risk function, Cournot model and government subsidy excitation function. The game laws of the closed-loop supply chain was analyzed, and the contract coordination mechanism was designed. The research results show that: 1) The third party recycler's competition does not affect the retailer's profit, order quantity and wholesale price, only affects the manufacturer's profit, third-party's profit, transfer price and the recycling price. 2) Government subsidy can raise manufacturer's and third-party's profits as well as heighten the enthusiasm of third-party's recycling. 3) The combination of risk-sharing contract and expense-sharing contract can make the closed-loop supply chain coordinated.

\section{References}

[1] Savaskan R C, Bhattacharya S, Van Wassenhove L N. Closed-loop supply chain models with product remanufacturing. Management Science, 2004, 50(2): 222-238.

[2] Bao X Y, Tang Z Y, Tang X W. Pricing strategy and coordination of closed-loop supply chain based on recycling and remanufacturing. Journal of System Management, 2010, 19(5): 546-552.

[3] Wang W B, Da Q L. The recycling and pricing study for the closed-loop supply chain of retailors and thirdparty recyclers. Journal of Industrial Engineering and Engineering Management, 2010, 24(2): 130-134.

[4] Zhang K Y, Zhou G H. Price decision analysis of closed-loop supply chain with retailers competition. Operation Research and Management Science, 2008, 17(6): 44-49.

[5] Webster S, Mitra S. Competitive strategy in remanufacturing and the impact of take-back laws. Journal of Operations Management, 2007, 25(6): 1123-1140.

[6] Wang S D, Zhou Y W. Newsvendor products supply chain coordination model considering lead compression. Control and Decision, 2010, 25(9): 1292-1296.

[7] Zhang F, Da Q L. Decision model for closed loop supply chain with uncertain demand and price-dependent returns. Journal of Southeast University (English Edition), 2010, 26(4): 638-641.

[8] Gan X H, Sethi S P, Yan H. Channel coordination with arisk-neutral supplier and a downside-risk-averse retailer. Production and Operations Management, 2005, 14(1): 80-89.

[9] Zhao D Z, He L F. The supply chain cooperation contract under downside-risk controls. Systems Engineering — Theory \& Practice, 2007, 4: 34-40.

[10] Yao Z. The coordination of return contract and supply chain within the risk constraint. Journal of Management Science in China, 2008, 11(3): 96-105.

[11] Ye F. The supply chain revenue-share contract mechanism with risk-aversion. Industrial Engineering and Management, 2006, 4: 50-53.

[12] Shi C D, Chen J H, Xiong T W. Closed-loop supply chain coordination for the third party's recycling. Operation Research and Management Science, 2011, 20(4): 39-47.

[13] Yao Z, Leung S C H, Lai K K. Manufacturer's revenue-sharing contract and retailer competition. European Journal of Operational Research, 2008, 186: 637-651.

[14] Telser L. Time safety-first and hedging. Review of Economic Studies, 1955, 23: 1-16.

[15] Shi C D, Chen J H, Wu Z J, et al. On closed-loop supply chain coordination with loss-averse retailer. Systems Engineering — Theory \& Practice, 2011, 31(9): 1668-1673.

[16] Yan X X. Logistics Aliance-Innovatiion Model Based on Logistics Service Capability. Economic Science Press, 2015. 